\title{
Deregulated microRNAs Are Associated with Patient Survival and Predicted to Target Genes That Modulate Lung Cancer Signaling Pathways
}

\author{
Cristiano P. Souza ${ }^{1,2,3}$, Naiara C. Cinegaglia ${ }^{2}$, Tainara F. Felix ${ }^{2}$, Adriane F. Evangelista ${ }^{3}{ }^{\circledR}$, \\ Rogério A. Oliveira $^{4}\left(\mathbb{D}\right.$, Erica N. Hasimoto ${ }^{1}$, Daniele C. Cataneo ${ }^{1} \mathbb{D}$, Antônio J. M. Cataneo ${ }^{1}(\mathbb{D}$, \\ Cristovam Scapulatempo Neto ${ }^{3}$, Cristiano R. Viana ${ }^{3}$, Flávia E. de Paula ${ }^{3}$, Sandra A. Drigo ${ }^{1,2} \mathbb{D}$, \\ Robson F. Carvalho ${ }^{5}$ (D) Márcia M. C. Marques ${ }^{3,6}$, Rui M. Reis ${ }^{3,7,8}$ (D) and Patricia P. Reis ${ }^{1,2, *(\mathbb{D})}$ \\ 1 Department of Surgery and Orthopedics, Faculty of Medicine, São Paulo State University, UNESP, \\ Botucatu 18618-687, SP, Brazil; crispeixoto10@hcancerbarretos.com.br (C.P.S.); \\ erica.hasimoto@unesp.br (E.N.H.); daniele.cataneo@unesp.br (D.C.C.); a.cataneo@unesp.br (A.J.M.C.); \\ sandra.d.linde@unesp.br (S.A.D.) \\ 2 Experimental Research Unity (UNIPEX), São Paulo State University, UNESP, Botucatu 18618-687, SP, Brazil; \\ naiara.cinegaglia@unesp.br (N.C.C.); tainara.felix@unesp.br (T.F.F.) \\ 3 Molecular Oncology Research Center, Barretos Cancer Hospital, Barretos 14784-400, SP, Brazil; \\ adriane.evangelista@hcancerbarretos.com.br (A.F.E.); cristovamscapula@uol.com.br (C.S.N.); \\ cristiano.viana.ext@dasa.com.br (C.R.V.); flavia.paula@hcancerbarretos.com.br (F.E.d.P.); \\ mmcmsilveira@gmail.com (M.M.C.M.); ruireis.hcb@gmail.com (R.M.R.) \\ 4 Department of Biostatistics, Plant Biology, Parasitology, and Zoology, Institute of Biosciences, \\ São Paulo State University UNESP, Botucatu 18618-689, SP, Brazil; rogerio.oliveira@unesp.br \\ 5 Department of Structural and Functional Biology, Institute of Biosciences, São Paulo State University, UNESP, \\ Botucatu 18618-689, SP, Brazil; robson.carvalho@unesp.br \\ 6 Barretos School of Health Sciences, Barretos 14785-002, SP, Brazil \\ 7 Life and Health Sciences Research Institute (ICVS), School of Medicine, University of Minho, \\ 4710-057 Braga, Portugal \\ 8 ICVS/3B's-PT Government Associate Laboratory, 410-057 Braga/Guimarães, Portugal \\ * Correspondence: patricia.reis@unesp.br; Tel.: +55-(14)-3880-1451
}

Received: 31 July 2020; Accepted: 9 September 2020; Published: 22 September 2020

Simple Summary: Lung cancer is the leading cause of cancer death, worldwide. The low survival rates are mainly due to disease diagnosis in advanced stages, and the lack of effective treatments. In this study, we analyzed molecules known as microRNAs, which regulate the expression of a large proportion of the human genes. microRNAs are involved in processes related to the development and progression of cancer. In lung cancer, many microRNAs can drive disease. This study showed that some microRNAs have aberrant levels in tumor cells of the two most common types of lung cancer: lung adenocarcinoma and squamous cell carcinoma. In addition, we found that one microRNA, named miR-25-3p, had aberrantly increased levels in tumor cells from patients who died of lung cancer. These results are useful to better understand the biology of lung cancer, and can contribute as an additional tool to predict patient outcome/survival.

\begin{abstract}
Background: Although the advances in diagnostic and treatment strategies, lung cancer remains the leading cause of cancer-related deaths, worldwide, with survival rates as low as $16 \%$ in developed countries. Low survival rates are mainly due to late diagnosis and the lack of effective treatment. Therefore, the identification of novel, clinically useful biomarkers is still needed for patients with advanced disease stage and poor survival. Micro(mi)RNAs are non-coding RNAs and potent regulators of gene expression with a possible role as diagnostic, prognostic and predictive biomarkers in cancer. (2) Methods: We applied global miRNA expression profiling analysis using TaqMan ${ }^{\circledR}$ arrays in paired tumor and normal lung tissues ( $n=38)$ from treatment-naïve patients with lung adenocarcinoma (AD; $n=23)$ and lung
\end{abstract}


squamous cell carcinoma (SCC; $n=15)$. miRNA target genes were validated using The Cancer Genome Atlas (TCGA) lung AD ( $n=561)$ and lung SCC $(n=523)$ RNA-Seq datasets. (3) Results: We identified 33 significantly deregulated miRNAs (fold change, $\mathrm{FC} \geq 2.0$ and $p<0.05$ ) in tumors relative to normal lung tissues, regardless of tumor histology. Enrichment analysis confirmed that genes targeted by the 33 miRNAs are aberrantly expressed in lung AD and SCC, and modulate known pathways in lung cancer. Additionally, high expression of miR-25-3p was significantly associated $(p<0.05)$ with poor patient survival, when considering both tumor histologies. (4) Conclusions: miR-25-3p may be a potential prognostic biomarker in non-small cell lung cancer. Genes targeted by miRNAs regulate $E G F R$ and TGF $\beta$ signaling, among other known pathways relevant to lung tumorigenesis.

Keywords: lung cancer; microRNAs; target genes; pathways; survival

\section{Introduction}

Lung cancer is the leading cause of cancer death worldwide. Current incidence data estimates over 2 million new cases/year, with $62 \%$ of cases occurring in developed countries, mainly in North America and Western countries, and 38\% in developing countries [1]. In Brazil, incidence data estimates the occurrence of approximately 30,000 new cases/year [2]. The 5-year survival rate remains low at approximately $19 \%$. The low survival rates are mainly due to late diagnosis, with only $15 \%$ of patients diagnosed with localized disease, $22 \%$ of patients with lymph node metastasis, $57 \%$ with distant metastasis and $6 \%$ with an undetermined disease stage [3].

Non-small cell lung cancer (NSCLC) comprises of the majority (85\%) of lung cancer cases, with adenocarcinoma (AD) and squamous cell carcinoma (SCC) as the two major histological subtypes. Invasive adenocarcinoma is further classified into histological subtypes of lepidic, solid, acinar, papillary and micropapillary; the latter has been associated with a worse prognosis [4].

Global efforts have been made, in order to determine actionable mutations in NSCLC, including The Cancer Genome Atlas (TCGA) project and the Lung Cancer Mutation Consortium (LCMC) $[5,6]$. TCGA comprehensively mapped mutations and transcriptome changes, as well as their frequency in large sample sets of lung AD and SCC, and demonstrated that mutations in oncogenes such as EGFR, $K-R A S, A L K$ and $B R A F$ occur in $>60 \%$ of lung AD cases [7], with driver mutations targetable by tyrosine kinase inhibitors [8]. The frequency of alterations of these driver genes in the Brazilian population is slightly different and associated with a genetic ancestry admixture [9-11]. Although the development of molecularly targeted therapies including EGFR tyrosine kinase inhibitors have benefited only a small fraction (15\%) of patients with lung AD. The majority of patients with advanced disease are still treated with chemotherapy regimens and survival rates remain low [12]. The identification of additional genes involved in signaling pathways may be useful as novel targets for NSCLC treatment. There is still a need to identify other biomarkers able to demonstrate clinical application in patient prognosis and prediction of the treatment response [12].

In the past decade, miRNAs have been discovered as potent gene expression regulators with an important role in disease development [13]. Previous studies have shown global deregulated miRNA expression profiles in lung cancer vs. normal tissues [14]. Here, we determined the expression of a 377 miRNA panel, using the TaqMan ${ }^{\circledR}$ Low Density Array platform, in primary lung AD and SCC, molecularly characterized for the major targeted genes, correlated miRNA expression with patient outcome/survival and mapped miRNA target genes in pathways associated with lung cancer. Our data adds to the current literature by showing that deregulated miRNAs modulate a number of genes encoding transcription factors, as well as common driver genes involved in lung tumor development and progression. 


\section{Results}

\subsection{Patient Clinical and Histopathological Characteristics}

Of the 38 samples included in the study, 23 patients were diagnosed with lung AD and 15 with lung SCC. Based on the new histological classification of lung AD, we identified the following subtypes: acinar $(n=9)$, solid $(n=5)$, papillary $(n=1)$, lepidic with acinar component $(n=4)$ and undetermined $(n=4)$. The mean age of patients with lung AD was 60.9 years, with a similar proportion of males and females (11 and 12, respectively). About 70\% of patients with lung AD were current or former smokers. Patients with lung SCC had an average age of 62 years, with a predominance of males (11 men and 4 women) and the vast majority (93.3\%) were active or former smokers. Patient clinical and histopathological characteristics are summarized in Table 1.

Table 1. Demographic and clinicopathological data of patients with lung adenocarcinoma (AD) and squamous cell carcinoma (SCC).

\begin{tabular}{cccc}
\hline Variables & AD & SCC & $p$ \\
\hline Age & & & \\
Mean (SD) & $60.91(10.3)$ & $62(7.1)$ & 0.725 \\
Range & $40-84$ & $51-73$ & \\
Sex & $\mathrm{N}(\%)$ & $\mathrm{N}(\%)$ & \\
Male & $13(56.5)$ & $11(73.4)$ & 0.329 \\
Female & $10(43.5)$ & $4(26.6)$ & \\
Smoking & $\mathrm{N}(\%)$ & $\mathrm{N}(\%)$ & \\
No & $7(30.5)$ & $1(6.7)$ & 0.114 \\
Yes & $16(69.5)$ & $14(93.3)$ & \\
Stage & $\mathrm{N}(\%)$ & $\mathrm{N}(\%)$ & \\
I & $9(39.1)$ & $4(26.7)$ & \\
II & $6(26.1)$ & $4(26.7)$ & 0.651 \\
III & $8(34.8)$ & $6(40)$ & \\
IV & 0 & $1(6.6)$ & \\
Death & $n(\%)$ & $n(\%)$ & \\
Cancer-associated & $5(62.5)$ & $4(44.4)$ & 0.637 \\
Other causes & $3(37.5)$ & $8(56.4)$ & \\
\hline
\end{tabular}

$n$ : number. Variables are not statistically significantly different between patients with lung AD and SCC.

Surgery was the primary treatment for all patients, except for one patient with stage IV disease at diagnosis, who was treated with chemotherapy. For this patient, the sample analyzed was a diagnostic biopsy obtained by lung bronchoscopy, before treatment. One patient died due to complications after surgery. Two patients developed tumor recurrence and one died of disease before palliative chemotherapy. One third of the patients received adjuvant chemotherapy (eight AD, 35\% and five SCC, 33\%) due to an advanced loco-regional disease (stages IB, II or III, 7th edition, Lung Cancer TNM Staging). Of these 13 patients, four developed distant metastasis requiring second line palliative chemotherapy, and two patients died due to tumor recurrence.

\subsection{EGFR and RAS Driver Mutations in Lung AD and SCC}

This analysis was performed to characterize common driver mutations (EGFR, K-RAS and N-RAS) in our sample set. Results showed three EGFR mutated tumors (13\% of lung AD cases), five K-RAS mutated tumors (two patients; $8.7 \%$ of AD cases and three patients; $20 \%$ of SCC cases), and one $N-R A S$ mutated tumor (6.7\% of SCC cases; Figure 1$)$. As expected, driver mutations were mutually exclusive. The occurrence of mutations was not associated with miRNA changes. 


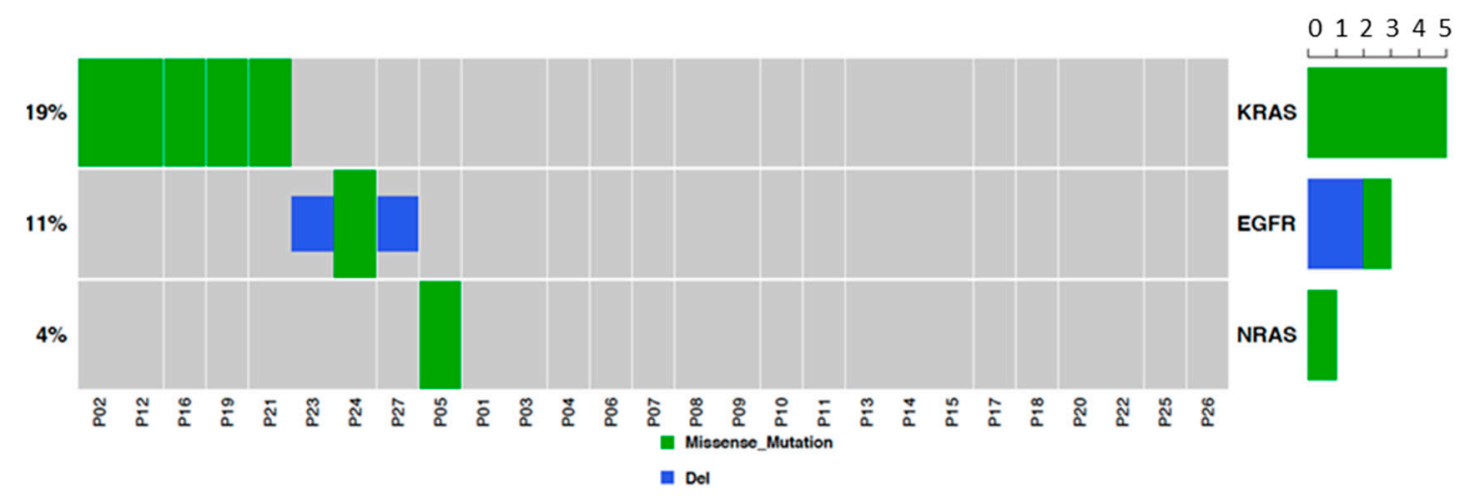

Figure 1. EGFR and KRAS mutation analysis. Two tumors were positive for KRAS p.Gly12Val, two were positive for KRAS p.Gly12Cys, one tumor was positive for KRAS p.Gly12Asp and one was positive for NRAS p.Gln61Arg and for KRAS p.Gln61His.

2.3. miRNAs Are Deregulated in Lung AD and SCC Compared to Normal Lung Tissues, and miR-25-3p Overexpression Is Significantly Associated with Poor Survival

Thirty-three miRNAs were detected as differentially expressed in tumors compared with normal samples, with the majority (31 miRNAs) being overexpressed (Table 2 , fold change $\geq 2$ and $p<0.05$ ).

Table 2. Significantly deregulated miRNAs in NSCLC, sorted based on fold change (FC) values, from lower to higher.

\begin{tabular}{ccc}
\hline miRNA & FC & $p$ Value of FC \\
\hline miR-143-3p & 0.326 & $<0.001$ \\
miR-140-5p & 0.369 & 0.049 \\
miR-376c-3p & 2.057 & 0.001 \\
miR-141-3p & 2.060 & 0.004 \\
miR-20a-5p & 2.107 & 0.003 \\
miR-199a-3p & 2.199 & 0.003 \\
miR-374-5p & 2.260 & $<0.001$ \\
miR-130a-3p & 2.414 & $<0.001$ \\
miR-29b-3p & 2.511 & $<0.001$ \\
let-7d-5p & 2.580 & $<0.001$ \\
miR-93-5p & 2.751 & $<0.001$ \\
miR-142-3p & 2.920 & 0.007 \\
miR-15a-5p & 3.016 & 0.017 \\
miR-155-5p & 3.056 & 0.005 \\
miR-25-3p * & 3.371 & $<0.001$ \\
miR-429 & 3.593 & $<0.001$ \\
miR-452-5p & 3.668 & 0.007 \\
miR-20b-5p & 3.917 & $<0.001$ \\
miR-135b-5p & 4.026 & $<0.001$ \\
miR-708-5p & 4.354 & $<0.001$ \\
miR-200b-3p & 4.446 & $<0.001$ \\
miR-340-5p & 5.345 & $<0.001$ \\
miR-744-5p & 5.649 & $<0.001$ \\
miR-365-3p & 5.766 & $<0.001$ \\
miR-205-5p & 5.856 & 0.001 \\
miR-590-5p & 6.112 & 0.001 \\
miR-224-5p & 6.692 & $<0.001$ \\
miR-15b-5p & 6.712 & $<0.001$ \\
miR-21-5p & 7.827 & $<0.001$ \\
\hline & & \\
\hline
\end{tabular}


Table 2. Cont.

\begin{tabular}{ccc}
\hline miRNA & FC & $p$ Value of FC \\
\hline miR-95-3p & 9.817 & $<0.001$ \\
miR-31-5p & 13.929 & 0.001 \\
miR-196b-5p & 16.525 & 0.001 \\
miR-411-5p & 25.909 & 0.033 \\
\hline
\end{tabular}

FC: fold change. Bolded miRNAs were associated with clinical data. ${ }^{*}$ indicates the miRNA correlated with lower overall survival.

Two miRNAs (miR-20a-5p and miR-93-5p) had higher expression levels in tumors from smokers compared to non-smokers ( $p<0.05)$. Larger tumor size (T3-T4) and the presence of lymph node metastasis (N1-N3) were associated with higher miR-29b-3pand lower miR-95-3p expression levels, respectively. miR-25-3p overexpression was significantly associated with overall survival, when considering patients with both tumor histologies (Figure 2).

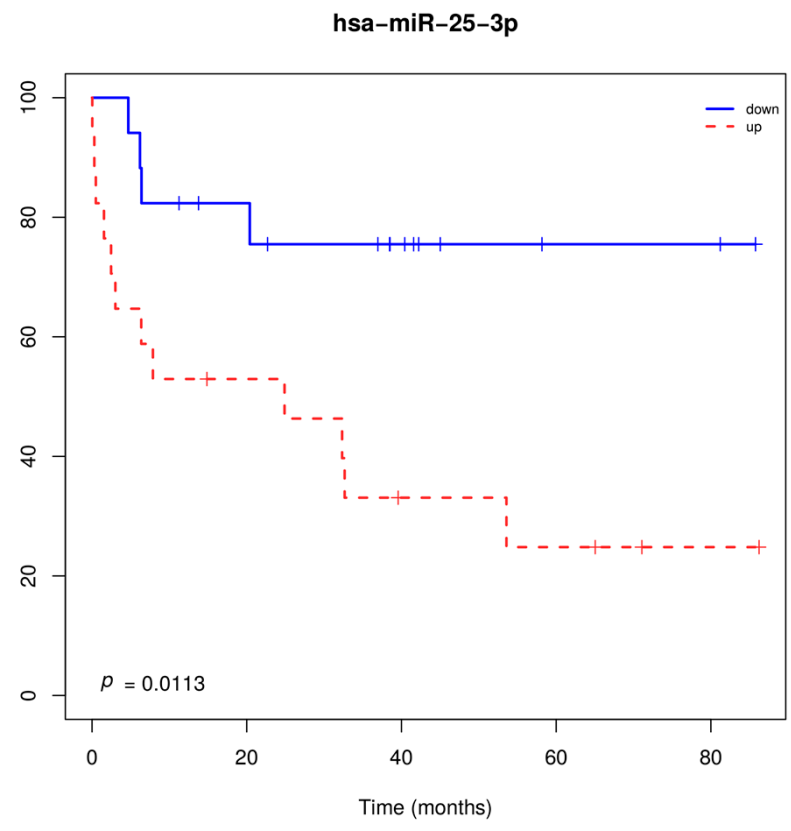

Figure 2. Overall survival of patients with lung carcinoma regardless of the histological subtype, according to miR-25-3p expression levels. Overexpression of miR-25-3p was associated with shorter overall survival.

In addition, we verified miR-25-3p expression in earlier stages (I/II; $n=639)$ and more advanced stages (III/IV; $n=147$ ) tumors versus controls. We found that miR-25-3p expression was significantly increased in stage I and II tumors vs. controls $(p=0.01022)$, and in more advanced stage tumors vs. controls $(p=0.02359)$. miR-25-3p expression levels were not significantly different between tumors from stages I/II vs. III/IV ( $p=0.4397$; Figure 3 ). 


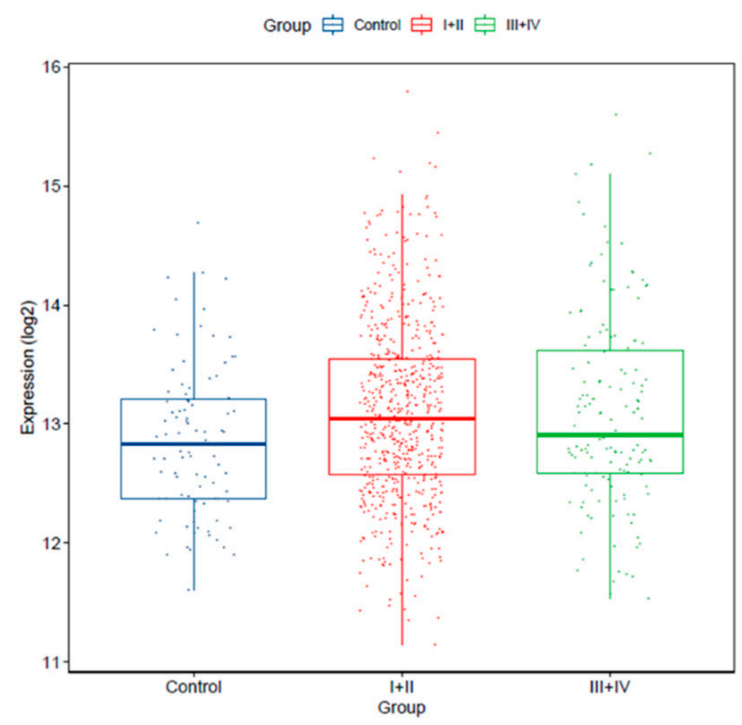

Figure 3. $\mathrm{miR}-25-3 \mathrm{p}$ expression levels is increased in stage I/II $(n=639 ; p=0.01022)$ and III/IV $(n=147$; $p=0.02359$ ) versus normal lung tissue (control, $n=91$; TCGA dataset).

Notably, a subset of miRNAs identified in our patient samples were aberrantly expressed in the lung AD and lung SCC-TCGA datasets, compared to paired normal lung tissues (Figure 4). Interestingly, miR-205-5 $p$ was confirmed as significantly overexpressed in our lung SCC, compared to lung AD samples $(p=0.0002)$.

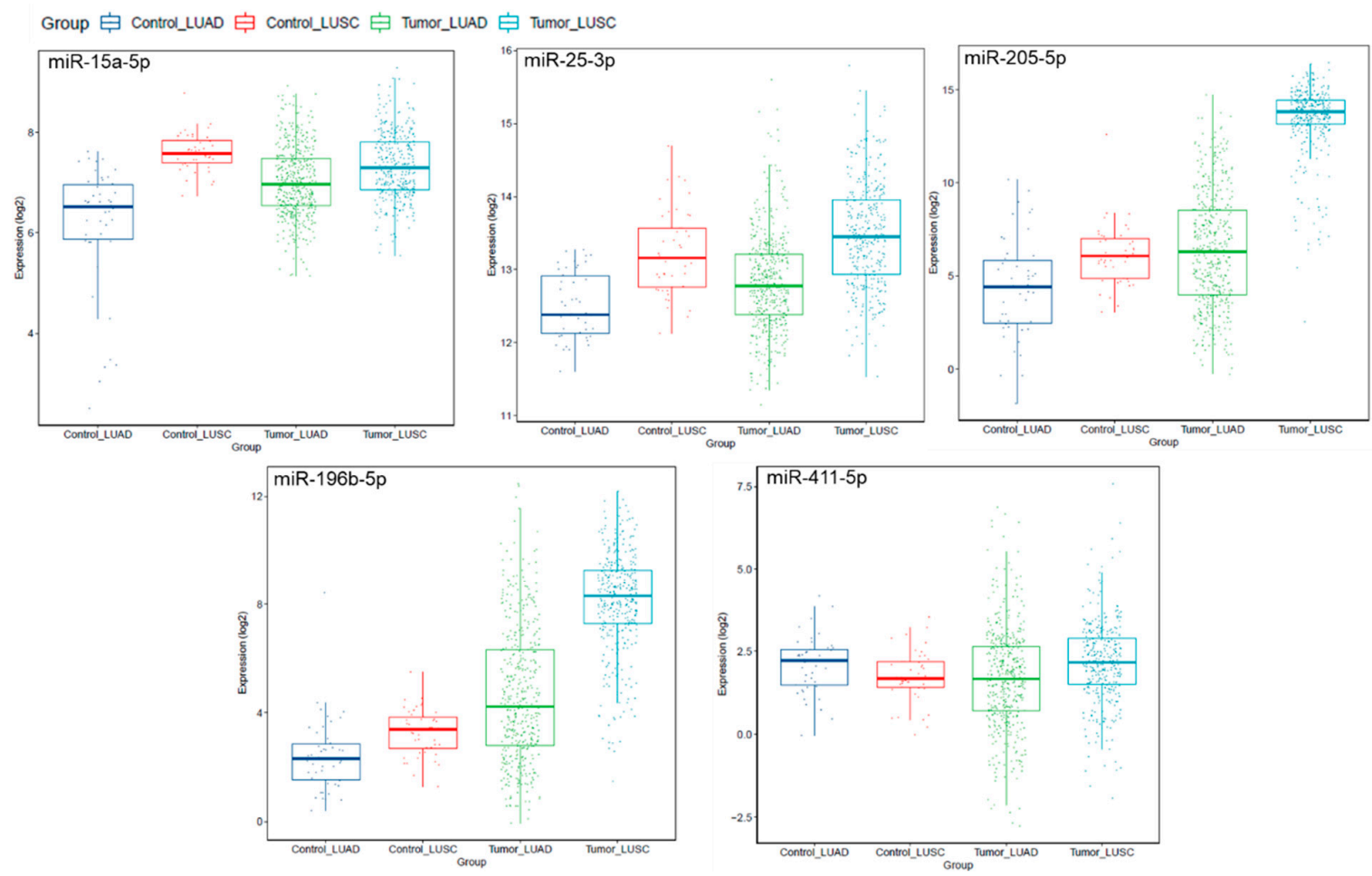

Figure 4. Expression levels of miRNAs miR-15a-5p, miR-25-3p, miR-205-5p, miR-196b-5p and miR-411-5p in lung adenocarcinoma (LUAD; $n=561$ ) and lung squamous cell carcinoma (LUSC; $n=523$ ), compared to normal lung tissues (control LUAD, $n=46$; control LUSC, $n=45$; TCGA dataset). This analysis shows miRNA expression levels by histological subtype, for better data visualization, since the TCGA data includes large sample sets. 
2.4. miRNAs Are Predicted to Regulate Genes Abnormally Expressed in Lung AD and SCC, which Modulate Known Pathways of Lung Cancer

We next evaluated the target genes potentially regulated by the 33 miRNAs identified in lung carcinomas. This analysis revealed various target genes involved in important biological functions in tumorigenesis such as transcriptional control. Interestingly, miRNAs validated in the TCGA dataset (miR-15a-5p, miR-25-3p, miR-205-5p, miR-196b-5p and miR-411-5p) were related to genes in cancer pathways. Considering all of the 33 deregulated miRNAs, significantly enriched pathways included EGFR and TGF $\beta$ signal transduction, which are known to be involved in lung cancer development and progression (Figure 5). Table S1 shows the complete list of enriched pathways, associated $p$-values and genes in each pathway.

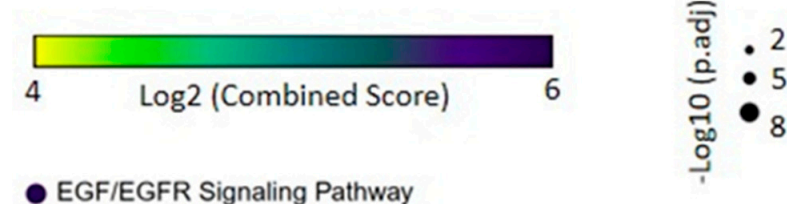

EGF/EGFR signaling pathway

Positive regulation of transcription, DNA-templated

Regulation of transcription from RNA polymerase II promoter

TGF-beta signaling pathway

MicroRNAs in cancer

Positive regulation of transcription from RNA polymerase II promoter

RNA polymerase II regulatory region sequence-specific DNA binding

Transcriptional activator activity, RNA polymerase II transcription regulatory region sequence-specific binding

TGF-beta Signaling Pathway

Transcription regulatory region sequence-specific DNA binding

Transmembrane receptor protein serine/threonine kinase activity

TGF-beta Receptor Signaling

p53 signaling pathway

TGF-beta signaling in development

ALK1 pathway

Transcriptional activator activity, RNA polymerase II core promoter proximal region sequence-specific binding

RNA polymerase II regulatory region DNA binding

Transcription factor activity, RNA polymerase II core promoter proximal region sequence-specific binding

Nuclear transcription factor complex

RNA polymerase II transcription factor complex

Downstream sianal transduction

BioPlanet
GO BP
GO BP
BioPlanet
KEGG
GO BP
GO MF
GO MF
WikiPathways
GO MF
GO MF
WikiPathways
KEGG
BioPlanet
BioPlanet
GO MF
GO MF
GO MF
GO CC
GO CC
Reactome

Figure 5. Gene set enrichment analysis of the predicted miRNA-target genes in lung cancer. Up to four of most significant terms from each of the following collections are shown: Kyoto Encyclopedia of Genes and Genomes (KEGG), WikiPathways, BioPlanet, Reactome, Gene Ontology (GO) biological process, GO molecular function and GO cellular component. The size and the color in the heat-scatterplot represent the combined score and the corresponding adjusted $p$-values, respectively, from the enrichment significance of each gene set, as computed by EnrichR $[15,16]$.

\section{Discussion}

miRNAs are gene expression regulators with a relevant role in tumorigenesis, including lung cancer [14]. miRNA alterations often lead to target gene deregulation and deregulated signaling pathways with roles in tumor development and progression [17-19]. Here, we reported 33 significantly deregulated miRNAs with the vast majority (31 miRNAs) being overexpressed in lung AD and SCC compared to paired normal lung tissues. A previous study by our group, conducted in a geographically distinct subset of patients, showed that circulating miRNAs in plasma from patients with lung AD and SCC have a predominant miRNA overexpression pattern. Interestingly, among miRNAs composing three plasma miRNA signatures, miR-155-5p overexpression was a common finding [20]. Notably, in a third, independent Brazilian patient lung adenocarcinoma subset, from our group, miR-155 and miR-21 were commonly overexpressed miRNAs in a paired analysis, in tumors compared to the normal tissue from the same patients [21].

In our patient dataset, higher miR-25-3p expression levels were positively correlated with overall patient survival $(p<0.05)$ including both tumor histologies. Deregulated miR-25 expression has 
been reported in human cancer [22,23], and overexpressed in NSCLC primary tumors and cell lines, associated with increased cell proliferation, migration and invasion [24]. miR-25 was further shown as overexpressed in NSCLC compared with paired normal lung tissues, and demonstrated to activate ERK signaling via KLF4, a miR-25 target gene, leading to increased tumor cell migration and invasion [25]. miR-25 overexpression was also associated with tumor progression and prognosis in lung adenocarcinoma [26], and shown to modulate radiation-induced apoptosis in radiotherapy-resistant tumors [27]. Conversely, downregulated miR-25 inhibited cell proliferation, induced G1 cell cycle arrest, increased cisplatin sensitivity and suppressed growth of cancer cell xenografts [28]. Additionally, high levels of miR-25 were detected in serum from NSCLC patients, associated with adverse prognostic factors such as tumor stage and lymph node metastasis, as well as overall survival and recurrence-free survival [29]. These data, along with our results, strongly suggest that miR-25 has a prognostic role in lung carcinoma.

In the TCGA NSCLC cohort, miR-25-3p overexpression was not associated with survival $(p=0.2)$, likely due to overrepresentation of earlier stage (I/II) lung AD and SCC tumors, which are often associated with better survival. In addition, while the TCGA dataset largely contributes to the validation of molecular changes associated with tumorigenesis mechanisms, previous reports suggested that uncurated data in large datasets might lead to biased correlation of biomarkers with clinical outcomes [30,31].

Other overexpressed miRNAs detected here, such as miR-196b-5p, were previously reported in lung cancer [32], and suggested to have a prognostic value in gastric cancer and glioblastoma [33,34]. Among the molecular targets of miR-196, Annexin 1 expression was associated with increased cell invasion [35], suggesting an oncogenic role in NSCLC. miR-196b upregulation was also demonstrated to promote cell invasion and morphological cellular alterations [36,37]. In addition, miR-205 has been identified by others [32,38-41] and suggested as a circulating biomarker with a diagnostic value in NSCLC [42]. Experimental evidence indicate that miR-205 acts in lung tumorigenesis through PTEN inactivation, promoting growth, migration, invasion and chemoresistance in NSCLC [43].

A limitation of our study is the small number of tumors, and a limited miRNA panel included in the analyses. In order to overcome this limitation, we included external miRNA expression validation in the large lung AD and SCC publicly available RNA-Seq datasets from TCGA.

Based on TCGA data, pathways activated by EGFR mutations were found in $11 \%$ of tumors, K-RAS mutations in 32\%, PI3K mutations in 4\%, HER2 in 3\% and PTEN inactivation in $3 \%$ of lung adenocarcinoma samples [6]. In lung SCC, TCGA data showed that pathways are often activated by mutations in TP53 in 81\% of tumors, PI3K in 16\%, PTEN in 15\%, EGFR in 9\%, KRAS in 3\% and HER2 in $4 \%$ of tumors [5]. Although we did not find mutations associated with miRNA changes, likely due to our small sample set, we identified common, mutually exclusive driver mutations in EGFR, K-RAS and $N-R A S$. In Brazilian patients, mutational frequency of driver genes was reported in a large number of lung adenocarcinoma cases $(n=444)$, with EGFR mutated in $22.7 \%$ and $K-R A S$ in $20.4 \%$ of the cases [9].

By computational analyses, we showed that deregulated miRNAs modulate a number of genes encoding transcription factors, as well as common driver genes in lung cancer. Enrichment analysis showed signal transduction pathways including EGFR, TGF $\beta$ and PI3K-AKT, which are implicated in lung tumor development and progression [44].

\section{Material and Methods}

\subsection{Ethics Statement}

This study was performed in accordance with the Declaration of Helsinki and national and international ethics guidelines. Our study has been approved by the Research Ethics Boards of the Faculty of Medicine, UNESP, Botucatu, SP (4319/2012) and Barretos Cancer Hospital, Barretos, SP (75907). 


\subsection{Patient Samples}

Fifty-eight formalin-fixed, paraffin-embedded (FFPE) tissue blocks were obtained from patients diagnosed with lung adenocarcinoma and squamous cell carcinoma. Patients have undergone surgery as the primary treatment, from 2007 to 2012, in two centers in the state of São Paulo; Botucatu Clinical Hospital and Barretos Cancer Hospital, SP, Brazil. All FFPE tissue samples were subjected to RNA and DNA extraction, as outlined below. Of these, 19 samples were excluded due to low RNA concentration. An additional nine histologically normal lung tissues, adjacent to their corresponding tumors, were collected and used as reference samples. Clinical and histopathological characteristics were obtained from medical records including age at diagnosis, gender, date of surgery, history of tobacco and alcohol exposure, disease grade and stage, type of primary treatment and/or adjuvant and/or palliative treatment, last date of follow-up and outcome. These data are shown in Table 1.

\subsection{RNA and DNA Extraction}

Samples obtained from FFPE tissue blocks were subjected to RNA extraction using the RecoverAll Total Nucleic Acid Isolation kit (Ambion/Life Technologies, Carlsbad, CA, USA), following a previously reported protocol with modifications to improve RNA yield [45]. RNA samples were quantified using NanoDrop 8000 (Thermo Fisher Scientific, Waltham, MA, USA) and quality was assessed using Bionalyzer 2100 (Agilent Technologies, Santa Clara, CA, USA), following the manufacturer's protocol. RNA samples were immediately stored at $-80^{\circ} \mathrm{C}$ until use for miRNA expression analysis.

In addition, DNA was isolated from representative sections of tumor FFPE resected samples, using the QIAmp DNA micro kit (Qiagen, Hilden, Germany) following the manufacturer's instructions as previously reported [9]. DNA was used for analysis of driver mutations by the SNaPShot assay.

\subsection{SNaPShot Assay}

Mutational analysis was performed using previously described primers without the MET primer, which was removed from the assay [45]. The PCR protocol was adapted as below, and performed in a final volume of $10 \mu \mathrm{L}$, with $50 \mathrm{ng}$ of DNA and $1 \mu \mathrm{M}$ of forward and reverse primers, using $5 \mu \mathrm{L}$ of the HotStar master mix multiplex (Qiagen, Hilden, Germany) according to the manufacturer's protocol, with the cycling parameters: $95^{\circ} \mathrm{C}$ for $15 \mathrm{~min}$, followed by 40 cycles of $95^{\circ} \mathrm{C}$ for $30 \mathrm{~s}, 60^{\circ} \mathrm{C}$ for $1 \mathrm{~min} .30 \mathrm{~s} ., 72{ }^{\circ} \mathrm{C}$ for $1 \mathrm{~min}$ and $72{ }^{\circ} \mathrm{C}$ for $30 \mathrm{~min}$ in a thermal cycler (Veriti, Applied Biosystems, Carlsbad, CA, USA). PCR products were purified with EXO-SAP (Affymetrix, Santa Clara, CA, USA) for $1 \mathrm{~h}$ for $37^{\circ} \mathrm{C}$ and $15 \mathrm{~min}$ for $80^{\circ} \mathrm{C}$. The SNaPShot assay was performed as multiplex extension reactions using $5 \mu \mathrm{L}$ of the reaction mix (SNapShot, Applied Biosystems) following the manufacturer's protocol, with the cycling parameters: $96{ }^{\circ} \mathrm{C}$ for $30 \mathrm{~s}$, followed by 35 cycles of $96{ }^{\circ} \mathrm{C}$ for $10 \mathrm{~s}, 50{ }^{\circ} \mathrm{C}$ for $5 \mathrm{~s}, 60^{\circ} \mathrm{C}$ for $30 \mathrm{~s}$ and $60^{\circ} \mathrm{C}$ for $10 \mathrm{~min}$ carried out in a thermal cycler (Veriti, Applied Biosystems, Carlsbad, CA, USA). The extension products were separated by electrophoresis in the ABI 3500 XL genetic analyzer (Applied Biosystems/Thermo Fisher Scientific); data were analyzed using the ABI GeneMapper, version 4.0 software (Applied Biosystems/Thermo Fisher Scientific).

\subsection{EGFR Exon 19 Deletion Analysis}

EGFR exon 19 deletions were evaluated using previously described primers [45]. The PCR assay was performed in a final volume of $15 \mu \mathrm{L}$, with 50ng of genomic DNA and $10 \mu \mathrm{M}$ of forward and reverse primers, using $7.5 \mu \mathrm{L}$ of the HotStar master mix (Qiagen, Hilden, Germany) following the manufacturer's protocol, with the cycling parameters: $96^{\circ} \mathrm{C}$ for $15 \mathrm{~min}$, followed by 40 cycles of $96^{\circ} \mathrm{C}$ for $45 \mathrm{~s}, 56.5^{\circ} \mathrm{C}$ for $45 \mathrm{~s}, 72{ }^{\circ} \mathrm{C}$ for $45 \mathrm{~s}$ and $72{ }^{\circ} \mathrm{C}$ for $10 \mathrm{~min}$ carried out in a thermal cycler (Veriti, Applied Biosystems, Carlsbad, CA, USA). The PCR products were separated by electrophoresis in the ABI3500 XL genetic analyzer (Applied Biosystems/Thermo Fisher Scientific) and data were analyzed using the ABI GeneMapper v.4.0 software (Applied Biosystems/Thermo Fisher Scientific). 


\subsection{EGFR Exon 20 Insertion Analysis}

A mutation analysis was performed using previously described primers [45]. The PCR assay was performed in a final volume of $15 \mu \mathrm{L}$, with 50ng of DNA and $10 \mu \mathrm{M}$ of forward and reverse primers, using $7.5 \mu \mathrm{L}$ of the HotStar master mix (Qiagen, Hilden, Germany) following the protocol proposed by the manufacturer, with the cycling parameters: $96^{\circ} \mathrm{C}$ for $15 \mathrm{~min}$, followed by 40 cycles of $96^{\circ} \mathrm{C}$ for $45 \mathrm{~s}$, $56.5^{\circ} \mathrm{C}$ for $45 \mathrm{~s}, 72{ }^{\circ} \mathrm{C}$ for $45 \mathrm{~s}$ and $72{ }^{\circ} \mathrm{C}$ for $10 \mathrm{~min}$ were carried out in a thermal cycler (Veriti, Applied Biosystems, Carlsbad, USA). PCR products were purified with EXOSAP (Affymetrix, Santa Clara, CA, USA) and subjected to direct sequencing using a BigDye Terminator cycle sequencing and BigDye $X$ Terminator purification kit (Applied Biosystems). The analysis was performed with the software Genetic Analyzer ABI PRISM 3500 and SeqScape version 2.7 (Applied Biosystems).

\subsection{Quantitative miRNA Expression Analysis by TaqMan Low Density Arrays}

miRNA expression was assessed by using the TaqMan ${ }^{\circledR}$ Array Human MicroRNA platform, card A, containing 377 miRNAs (Life Technologies, Foster City, CA, USA), as previously described [46]. Briefly, the reverse transcription mix was prepared using Megaplex primers, followed by preparation of the quantitative PCR mix $(450 \mu \mathrm{L}$ of amplification mix plus $6 \mu \mathrm{L}$ of newly synthesized cDNA, added to $444 \mu \mathrm{L}$ of nuclease-free ddH2O (Sigma, St. Louis, MI, USA)). Of this mix $100 \mu \mathrm{L}$ was added to the cards containing lyophilized miRNA probes; the cards were then centrifuged and loaded into the QuantStudio 12K instrument (Life Technologies, Foster City, CA, USA). miRNA expression profiles were determined in a total of 41 samples (38 tumors and 3 pools of 9 histologically normal lung tissues from a subset of the patients. Each pooled control contained three normal lung samples. Pooled samples were prepared after RNA extraction from each sample. Global normalization was performed using the Expression Suite software (Life Technologies, Foster City, CA, USA) using the stably expressed endogenous controls RNU-44, RNU-48 and U6, and compared to pools of normal lung samples.miRNA expression profiles were determined using the RQ Manager v.1.2 software (Life Technologies, Foster City, CA, USA), and the Delta Delta Ct method [47].

\subsection{Computational and Statistical Analyses}

Data from the TCGA dataset was retrieved using FirebrowseR [48]. Predicted miRNA target genes were identified using miRWalk v. 3.0 (http://mirwalk.umm.uni-heidelberg.de/) [49] by integrating the prediction results of TargetScan [50], miRDB [51] and miRTarBase [52], and considering a score $\geq 0.95$ as the screening threshold. The predicted targets were used to perform a comprehensive gene set enrichment analysis with EnrichR links (http://amp.pharm.mssm.edu/Enrichr/) [15,16,53]. The enrichment results of the top ten terms from each EnrichR link were represented by the $p$-value (Fisher's exact test) and $\mathrm{Z}$ score (correction to the test) in a combined score $[15,16]$. A heat scatterplot for the enrichment results was created using the web tool Morpheus [54] (https://software.broadinstitute.org/morpheus) [55].

\section{Conclusions}

miR-25-3p overexpression may have prognostic relevance in lung AD and SCC. In addition, our data support the existing literature by identifying miRNAs predicted to modulate transcription factors and known driver genes with a role in lung cancer pathways. Our data show that different miRNAs are biologically relevant in NSCLC.

Supplementary Materials: The following are available online at http://www.mdpi.com/2072-6694/12/9/2711/s1, Table S1: List of enriched pathways, associated $p$-values and genes in each pathway.

Author Contributions: Conceptualization: C.P.S., M.M.C.M., R.M.R. and P.P.R.; Data curation: N.C.C., T.F.F., A.F.E., R.A.O., S.A.D. and R.F.C.; Formal analysis: C.P.S., A.F.E., R.A.O., S.A.D. and R.F.C.; Funding acquisition: P.P.R. and R.M.R.; Investigation: E.N.H., D.C.C., A.J.M.C., C.S.N., C.R.V. and F.E.d.P.; Methodology: C.P.S., N.C.C. and T.F.F.; Project administration: P.P.R.; Resources: R.M.R. and P.P.R.; Supervision: P.P.R.; Validation: A.F.E. and R.F.C.; Writing—original draft: C.P.S., S.A.D., R.F.C., M.M.C.M., R.M.R. and P.P.R.; Writing—review and editing: all authors. All authors have read and agreed to the published version of the manuscript. 
Funding: This research was funded by the São Paulo Research Foundation (FAPESP, grant \# 2011/13213-7, PP Reis) and FINEP (CT-INFRA, 02/2010, RMR). The funders had no role in the study design, data collection and analysis, decision to publish or preparation of the manuscript.

Conflicts of Interest: The authors declare that they have no competing interest.

\section{References}

1. Bray, F.; Ferlay, J.; Soerjomataram, I.; Siegel, R.L.; Torre, L.A.; Jemal, A. Global cancer statistics 2018: GLOBOCAN estimates of incidence and mortality worldwide for 36 cancers in 185 countries. CA Cancer J. Clin. 2018, 68, 394-424. [CrossRef]

2. Estimativa 2020: Incidência de Câncer no Brasil INCA - Instituto Nacional de Câncer. Available online: https://www.inca.gov.br/publicacoes/livros/estimativa-2020-incidencia-de-cancer-no-brasil (accessed on 31 July 2020).

3. Siegel, R.L.; Miller, K.D.; Jemal, A. Cancer statistics, 2020. CA Cancer J. Clin. 2020, 70, 7-30. [CrossRef] [PubMed]

4. Travis, W.D.; Brambilla, E.; Nicholson, A.G.; Yatabe, Y.; Austin, J.H.M.; Beasley, M.B.; Chirieac, L.R.; Dacic, S.; Duhig, E.; Flieder, U.B.; et al. The 2015 World Health Organization Classification of Lung Tumors. J. Thorac. Oncol. 2015, 10, 1243-1260. [CrossRef] [PubMed]

5. Hammerman, P.S.; Voet, D.; Lawrence, M.S.; Voet, D.; Jing, R.; Cibulskis, K.; Sivachenko, A.; Stojanov, P.; McKenna, A.; Lander, E.S.; et al. Comprehensive genomic characterization of squamous cell lung cancers. Nature 2012, 489, 519-525.

6. The Cancer Genome Atlas Research Network; Cancer Genome Atlas Research Network; Collisson, E.A.; Berger, A.H.; Beer, D.G.; Hammerman, P.S.; Herman, J.G.; Jurisica, I.; Kwiatkowski, D.; Robertson, G.; et al. Comprehensive molecular profiling of lung adenocarcinoma. Nature 2014, 511, 543-550. [CrossRef]

7. Chang, J.T.-H.; Lee, Y.-M.; Huang, R.S. The impact of the Cancer Genome Atlas on lung cancer. Transl. Res. 2015, 166, 568-585. [CrossRef] [PubMed]

8. Kris, M.G.; Johnson, B.E.; Berry, L.D.; Kwiatkowski, D.J.; Iafrate, A.J.; Wistuba, I.I.; Varella-Garcia, M.; Franklin, W.A.; Aronson, S.L.; Su, P.-F.; et al. Using Multiplexed Assays of Oncogenic Drivers in Lung Cancers to Select Targeted Drugs. JAMA 2014, 311, 1998. [CrossRef]

9. Leal, L.F.; De Paula, F.E.; De Marchi, P.; Viana, L.D.S.; Pinto, G.D.J.; Carlos, C.D.; Berardinelli, G.N.; Miziara, J.E.; Da Silva, C.M.; Silva, E.C.A.; et al. Mutational profile of Brazilian lung adenocarcinoma unveils association of EGFR mutations with high Asian ancestry and independent prognostic role of KRAS mutations. Sci. Rep. 2019, 9, 3209. [CrossRef]

10. Andreis, T.F.; Correa, B.S.; Vianna, F.S.; De-Paris, F.; Siebert, M.; Leistner-Segal, S.; Hahn, E.C.; Ulbrich, J.M.; Rivero, L.F.; De Oliveira, F.H.; et al. Analysis of Predictive Biomarkers in Patients With Lung Adenocarcinoma From Southern Brazil Reveals a Distinct Profile From Other Regions of the Country. J. Glob. Oncol. 2019, 5, 1-9. [CrossRef]

11. Palacio, S.; Pontes, L.; Prado, E.; Arshad, J.; Ali, R.; Piha, T.; Bacchi, C.E.; Mudad, R.; Lopes, G. EGFR Mutation Testing: Changing Patterns of Molecular Testing in Brazil. Oncol. 2018, 24. [CrossRef]

12. Larsen, J.E.; Minna, J.D. Molecular Biology of Lung Cancer: Clinical Implications. Clin. Chest Med. 2011, 32, 703-740. [CrossRef] [PubMed]

13. Iorio, M.V.; Croce, C.M. MicroRNA dysregulation in cancer: Diagnostics, monitoring and therapeutics. A comprehensive review. EMBO Mol. Med. 2012, 4, 143-159. [CrossRef] [PubMed]

14. Iqbal, M.A.; Arora, S.; Prakasam, G.; Calin, G.A.; Syed, M.A. MicroRNA in lung cancer: Role, mechanisms, pathways and therapeutic relevance. Mol. Asp. Med. 2019, 70, 3-20. [CrossRef] [PubMed]

15. Chen, E.Y.; Tan, C.M.; Kou, Y.; Duan, Q.; Wang, Z.; Meirelles, G.V.; Clark, N.R.; Ma'Ayan, A. Enrichr: Interactive and collaborative HTML5 gene list enrichment analysis tool. BMC Bioinform. 2013, 14, 128. [CrossRef] [PubMed]

16. Kuleshov, M.V.; Jones, M.R.; Rouillard, A.D.; Fernandez, N.F.; Duan, Q.; Wang, Z.; Koplev, S.; Jenkins, S.L.; Jagodnik, K.M.; Lachmann, A.; et al. Enrichr: A comprehensive gene set enrichment analysis web server 2016 update. Nucleic Acids Res. 2016, 44, W90-W97. [CrossRef] [PubMed]

17. Liang, Y. An expression meta-analysis of predicted microRNA targets identifies a diagnostic signature for lung cancer. BMC Med. Genom. 2008, 1, 61. [CrossRef] 
18. Macfarlane, L.-A.; Murphy, P.R. MicroRNA: Biogenesis, Function and Role in Cancer. Curr. Genom. 2010, 11, 537-561. [CrossRef]

19. Tsai, Y.-M.; Tsai, Y.-M.; Lien, C.-T.; Kuo, P.-L.; Hung, A.J.-Y.; Hung, J.-Y. The Roles of MicroRNA in Lung Cancer. Int. J. Mol. Sci. 2019, 20, 1611. [CrossRef]

20. Reis, P.; Drigo, S.A.; Carvalho, R.; Lapa, R.M.L.; Felix, T.F.; Patel, D.; Cheng, D.; Pintilie, M.; Liu, G.; Tsao, M.-S. Circulating miR-16-5p, miR-92a-3p, and miR-451a in Plasma from Lung Cancer Patients: Potential Application in Early Detection and a Regulatory Role in Tumorigenesis Pathways. Cancers 2020, 12, 2071. [CrossRef]

21. Cinegaglia, N.C.; Andrade, S.C.S.; Tokar, T.; Pinheiro, M.; Severino, F.E.; Oliveira, R.A.; Hasimoto, E.N.; Cataneo, D.C.; Cataneo, A.J.M.; Defaveri, J.; et al. Integrative transcriptome analysis identifies deregulated microRNA-transcription factor networks in lung adenocarcinoma. Oncotarget 2016, 7, 28920-28934. [CrossRef]

22. Wang, C.; Ding, M.; Xia, M.; Chen, S.; Van Le, A.; Soto-Gil, R.W.; Shen, Y.; Wang, N.; Wang, J.; Gu, W.; et al. A Five-miRNA Panel Identified From a Multicentric Case-control Study Serves as a Novel Diagnostic Tool for Ethnically Diverse Non-small-cell Lung Cancer Patients. EBioMedicine 2015, 2, 1377-1385. [CrossRef] [PubMed]

23. Caiazza, C.; Mallardo, M. The Roles of miR-25 and its Targeted Genes in Development of Human Cancer. MicroRNA 2016, 5, 113-119. [CrossRef] [PubMed]

24. Xiang, J.; Hang, J.-B.; Che, J.-M.; Li, H. miR-25 is up-regulated in non-small cell lung cancer and promotes cell proliferation and motility by targeting FBXW7. Int. J. Clin. Exp. Pathol. 2015, 8, 9147-9153. [PubMed]

25. Ding, X.; Zhong, T.; Jiang, L.; Huang, J.; Xia, Y.; Hu, R. miR-25 enhances cell migration and invasion in non-small-cell lung cancer cells via ERK signaling pathway by inhibiting KLF4. Mol. Med. Rep. 2018, 17, 7005-7016. [CrossRef] [PubMed]

26. Xu, F.-X.; Su, Y.; Zhang, H.; Kong, J.-Y.; Yu, H.; Qian, B.-Y. Prognostic Implications for High Expression of MiR-25 in Lung Adenocarcinomas of Female Non-smokers. Asian Pac. J. Cancer Prev. 2014, 15, 1197-1203. [CrossRef]

27. He, Z.; Liu, Y.; Xiao, B.; Qian, X. miR-25 modulates NSCLC cell radio-sensitivity through directly inhibiting BTG2 expression. Biochem. Biophys. Res. Commun. 2015, 457, 235-241. [CrossRef] [PubMed]

28. Yang, T.; Chen, T.; Li, Y.; Gao, L.; Zhang, S.; Wang, T.; Chen, M. Downregulation of miR-25 modulates non-small cell lung cancer cells by targeting CDC42. Tumor Boil. 2014, 36, 1903-1911. [CrossRef]

29. Li, J.; Yu, M.; Liu, Z.; Liu, B. Clinical significance of serum miR-25 in non-small-cell lung cancer. Br. J. Biomed. Sci. 2019, 76, 111-116. [CrossRef]

30. Peran, I.; Madhavan, S.; Byers, S.W.; McCoy, M.D. Curation of the Pancreatic Ductal Adenocarcinoma Subset of the Cancer Genome Atlas Is Essential for Accurate Conclusions about Survival-Related Molecular Mechanisms. Clin. Cancer Res. 2018, 24, 3813-3819. [CrossRef]

31. Nicolle, R.; Raffenne, J.; Paradis, V.; Couvelard, A.; De Reyniès, A.; Blum, Y.; Cros, J. Prognostic Biomarkers in Pancreatic Cancer: Avoiding Errata When Using the TCGA Dataset. Cancers 2019, 11, 126. [CrossRef]

32. Hamamoto, J.; Soejima, K.; Yoda, S.; Naoki, K.; Nakayama, S.; Satomi, R.; Terai, H.; Ikemura, S.; Sato, T.; Yasuda, H.; et al. Identification of microRNAs differentially expressed between lung squamous cell carcinoma and lung adenocarcinoma. Mol. Med. Rep. 2013, 8, 456-462. [CrossRef] [PubMed]

33. Lim, J.Y.; Yoon, S.O.; Seol, S.-Y.; Hong, S.W.; Kim, J.W.; Choi, S.H.; Lee, J.-S.; Cho, J.Y. Overexpression of miR-196b and HOXA10 characterize a poor-prognosis gastric cancer subtype. World J. Gastroenterol. 2013, 19, 7078-7088. [CrossRef] [PubMed]

34. Ma, R.; Yan, W.; Zhang, G.; Lv, H.; Liu, Z.; Fang, F.; Zhang, W.; Zhang, J.; Tao, T.; You, Y.; et al. Upregulation of miR-196b Confers a Poor Prognosis in Glioblastoma Patients via Inducing a Proliferative Phenotype. PLoS ONE 2012, 7, e38096. [CrossRef] [PubMed]

35. Liu, Y.-F.; Zhang, P.-F.; Li, M.-Y.; Li, Q.-Q.; Chen, Z.-C. Identification of annexin A1 as a proinvasive and prognostic factor for lung adenocarcinoma. Clin. Exp. Metastasis 2011, 28, 413-425. [CrossRef] [PubMed]

36. Yu, S.-L.; Lee, D.C.; Sohn, H.A.; Lee, S.Y.; Jeon, H.S.; Lee, J.H.; Park, C.G.; Lee, H.Y.; Yeom, Y.I.; Son, J.W.; et al. Homeobox A9 directly targeted by miR-196b regulates aggressiveness through nuclear Factor-kappa B activity in non-small cell lung cancer cells. Mol. Carcinog. 2015, 55, 1915-1926. [CrossRef] [PubMed]

37. Li, H.; Feng, C.; Shi, S. miR-196b promotes lung cancer cell migration and invasion through the targeting of GATA6. Oncol. Lett. 2018, 16, 247-252. [CrossRef] [PubMed] 
38. Bishop, J.A.; Benjamin, H.; Cholakh, H.; Chajut, A.; Clark, D.P.; Westra, W.H. Accurate Classification of Non-Small Cell Lung Carcinoma Using a Novel MicroRNA-Based Approach. Clin. Cancer Res. 2010, 16, 610-619. [CrossRef]

39. Patnaik, S.K.; Yendamuri, S.; Mallick, R.; Dhillon, S.S. Reply to "MiR-205 and miR-375 microRNA Assays to Distinguish Squamous Cell Carcinoma From Adenocarcinoma in Lung Cancer Biopsies". J. Thorac. Oncol. 2015, 10, e53. [CrossRef]

40. Solomides, C.; Evans, B.J.; Navenot, J.-M.; Vadigepalli, R.; Peiper, S.C.; Wang, Z. MicroRNA Profiling in Lung Cancer Reveals New Molecular Markers for Diagnosis. Acta Cytol. 2012, 56, 645-654. [CrossRef]

41. Lebanony, D.; Benjamin, H.; Gilad, S.; Ezagouri, M.; Dov, A.; Ashkenazi, K.; Gefen, N.; Izraeli, S.; Rechavi, G.; Pass, H.; et al. Diagnostic Assay Based on hsa-miR-205 Expression Distinguishes Squamous From Nonsquamous Non-Small-Cell Lung Carcinoma. J. Clin. Oncol. 2009, 27, 2030-2037. [CrossRef]

42. Jiang, M.; Zhang, P.; Hu, G.; Xiao, Z.; Xu, F.; Zhong, T.; Huang, F.; Kuang, H.-B.; Zhang, W. Relative expressions of miR-205-5p, miR-205-3p, and miR-21 in tissues and serum of non-small cell lung cancer patients. Mol. Cell. Biochem. 2013, 383, 67-75. [CrossRef] [PubMed]

43. Lei, L.; Huang, Y.; Gong, W. miR-205 promotes the growth, metastasis and chemoresistance of NSCLC cells by targeting PTEN. Oncol. Rep. 2013, 30, 2897-2902. [CrossRef] [PubMed]

44. Herbst, R.S.; Heymach, J.V.; Lippman, S.M. Molecular origins of cancer: Lung cancer. N. Engl. J. Med. 2008, 359, 1367-1380. [CrossRef] [PubMed]

45. Su, Z.; Dias-Santagata, D.; Duke, M.; Hutchinson, K.; Lin, Y.-L.; Borger, D.R.; Chung, C.H.; Massion, P.P.; Vnencak-Jones, C.L.; Iafrate, A.J.; et al. A Platform for Rapid Detection of Multiple Oncogenic Mutations with Relevance to Targeted Therapy in Non-Small-Cell Lung Cancer. J. Mol. Diagn. 2011, 13, 74-84. [CrossRef] [PubMed]

46. Goswami, R.S.; Waldron, L.; Machado, J.; Cervigne, N.K.; Xu, W.; Reis, P.; Bailey, D.; Jurisica, I.; Crump, M.; Kamel-Reid, S. Optimization and analysis of a quantitative real-time PCR-based technique to determine microRNA expression in formalin-fixed paraffin-embedded samples. BMC Biotechnol. 2010, 10, 47. [CrossRef] [PubMed]

47. Livak, K.J.; Schmittgen, T.D. Analysis of relative gene expression data using real-time quantitative PCR and the 2(-Delta Delta C(T)) method. Methods 2001, 25, 402-408. [CrossRef]

48. Deng, M.; Brägelmann, J.; Kryukov, I.; Saraiva-Agostinho, N.; Perner, S. FirebrowseR: An R client to the Broad Institute's Firehose Pipeline. Database 2017, 2017. [CrossRef] [PubMed]

49. Home-miRWalk. Available online: http://mirwalk.umm.uni-heidelberg.de/ (accessed on 20 August 2020).

50. Agarwal, V.; Bell, G.W.; Nam, J.-W.; Bartel, B. Predicting effective microRNA target sites in mammalian mRNAs. eLife 2015, 4, 4. [CrossRef]

51. Wong, N.; Wang, X. miRDB: An online resource for microRNA target prediction and functional annotations. Nucleic Acids Res. 2014, 43, D146-D152. [CrossRef]

52. Chou, C.-H.; Shrestha, S.; Yang, C.-D.; Chang, N.-W.; Lin, Y.-L.; Liao, K.-W.; Huang, W.-C.; Sun, T.-H.; Tu, S.-J.; Lee, W.-H.; et al. miRTarBase update 2018: A resource for experimentally validated microRNA-target interactions. Nucleic Acids Res. 2018, 46, D296-D302. [CrossRef]

53. Enrichr. Available online: https://maayanlab.cloud/Enrichr/ (accessed on 20 August 2020).

54. Starruß, J.; De Back, W.; Brusch, L.; Deutsch, A. Morpheus: A user-friendly modeling environment for multiscale and multicellular systems biology. Bioinformatics 2014, 30, 1331-1332. [CrossRef] [PubMed]

55. Morpheus. Available online: https://software.broadinstitute.org/morpheus/ (accessed on 20 August 2020).

(C) 2020 by the authors. Licensee MDPI, Basel, Switzerland. This article is an open access article distributed under the terms and conditions of the Creative Commons Attribution (CC BY) license (http://creativecommons.org/licenses/by/4.0/). 